\title{
RITO Y MEDICINA EN LOS SANADORES MORISCOS
}

Por

JESÚS MAISO

\section{Aproximación a la medicina morisca}

En un reciente libro, Luis García Ballester ha puesto al día sus estudios sobre la medicina y la práctica médica de los moriscos (1). Este profesor nos recuerda cómo la penetración de la ciencia médica de la antigüedad se produjo en la Europa latina medieval a través de las traducciones al latín de la literatura médica de los árabes. La ciencia médica medieval europea estaba constituida por el llamado «galenismo arabizado». «El núcleo del galenismo arabizado apenas era otra cosa que el comentario escolástico al Canon de Avicena en su versión latina medieval de Gerardo de Cremona; en muchas ocasiones este texto es incomprensible, a diferencia del original árabe. Estos galenistas fueron incapaces de replantear sus puntos de vista sobre Avicena desde el contacto directo con el propio Avicena» (2). Para apropiarse de la ciencia médica árabe y vitalizar asi el galenismo arabizado, hubiera sido necesario adoptar una actitud frente a la cultura y el mundo árabe muy distinta de la que se siguió. Pero el rechazo y la persecución de su lengua y su cultura impidieron el remozamiento del galenismo arabizado en España.

Ni siquiera en el plano intelectual se protegió el conocimiento del árabe, pues en la universidad española del s. XVI no llegó a afianzarse la enseñanza de la lengua árabe.

Como consecuencia el galenismo arabizado acabó por parecer un arcaísmo y una tradición trasnochada ante el prestigio del humanismo renacentista que se acercaba a las fuentes de la medicina a través de la nueva ciencia filológica.

(1) GARCIA BALLESTER, L: Los moriscos y la medicina. Un capitulo de la medicina y la ciencia marginadas en la España del s. XVI, Barcelona, 1984.

(2) Ibidem, pp. 22-23. 
Sin embargo la antigüedad y la fidelidad de las versiones árabes de las obras de Galeno hubieran permitido una mejor y más amplia recuperación de éstas, y de las demás fuentes griegas, que habrian iluminado los puntos oscuros y las obras perdidas de los clásicos. Los intentos de utilizar los códices árabes en España como medio para acceder a las obras de Hipócrates y Galeno carecieron de fuerza, de continuidad y en definitiva de éxito. Jerónimo Ledesma en su deseo de superar la «traducción bárbara» del Canon de Avicena, que había realizado Gerardo de Cremona, emprendió la traducción directa desde el árabe al latín, propósito que no llevó a término por su repentina muerte.

«El árabe nunca fue incorporado al programa del humanismo médico en su esfuerzo por reconstruir la medicina antigua, incluso aunque alguno considerara lo mejor de la medicina árabe como parte de su propia herencia» (3). De este modo el galenismo del renacimiento se alejó cada vez más de los autores árabes y miro a Hipócrates con preferencia.

El profesor García Ballester se detiene también en la preparación de los médicos moriscos y en el control social de esta actividad. En primer lugar, en la cultura árabe la medicina «no llegó a cristalizar socialmente como una profesión de acuerdo con los indicadores externos generados en el occidente latino bajomedieval» (4). Sin embargo, se habia desmarcado del curanderismo a través del aval o «ŷaza» que acreditaba en el aspecto docente, no en el profesional, al médico árabe.

Tras la conquista de Granada siguió perviviendo, entre la población musulmana y morisca, el médico de preparación científica que se veía a sí mismo en oposición a las diversas formas de curanderismo. Al crearse la Universidad de Granada, en la primera mitad del s. XVI, se podian cursar en esta ciudad los estudios de medicina. En la Facultad de Medicina de Granada - la más modesta de las facultades de esta Universidad- se sabe que al menos dos moriscos cursaron estudios de medicina. Uno de ellos, Alonso de Castillo (c. 1520-c. 1607), además de conocer el giriego y el latín, dominaba perfectamente el árabe clásico y estaba al tanto de la medicina árabe de los mejores tiempos. Sin embargo, el recelo de la cultura árabe por parte de los cristianos viejos impidió que estos médicos moriscos pudieran vivificar los estudios médicos de aquella modesta facultad de medicina.

También en Valencia se sabe de moriscos que estudiaron medicina. En 1547 está censado el «metge moro» Gomis Fajardo; por desgracia los libros de la Tacha Real de Valencia terminaron en 1552, y a partir de esta fecha no podemos conocer el censo de los médicos de la ciudad. Pero si hacemos caso de Bleda, en los años finales del S. XVl algunos médicos moriscos se doctoraron en medicina por la universidad valenciana (5).

El clima intolerante de la sociedad cristiana vertió sobre la figura del profesional médico morisco las más diversas calumnias y descalificaciones. Se intentó cerrarles los caminos de su ascenso social, impidiéndoles la entrada en las facultades de medicina y hasta la misma práctica médica.

(3) Ibidem, p. 38

(4) Ibídem, p. 48.

(5) BLEDA, I.: Defensio fidei in causa neophitorum sive morischorum Regni Valentiae, Valencia, 1610, p. 368. 
Asi los médicos moriscos al no poder acceder a las fuentes árabes -los libros en esta lengua están prohibidos - ni a la universidad vieron degradada su ciencia que se aproximó cada vez más al mundo de los curanderos. Progresivamente médicos, sanadores, curanderos y toda la multitud de gentes que atendian los problemas sanitarios de la población morisca tendían a identificarse por abajo a causa de la desintegración de la cultura árabe en general, y de la ciencia médica árabe en particular.

\section{La medicina popular de los moriscos}

Por todo ello, la medicina de los moriscos tiende a identificarse cada vez más con la medicina popular.

El trabajo de García Ballester se centra preferentemente en los aspectos que vinculan el quehacer de los sanadores moriscos con la medicina académica árabe, incluso con la humanista.

Mi análisis se va a centrar en la vertiente popular de su práctica médica.

No conviene olvidar que la medicina popular ha estado al servicio de las grandes masas de población al menos hasta el s. XVIII, frente a la medicina académica, privativa de minorías hasta época reciente, y con frecuencia mezclada con la medicina popular.

En el mundo rural agrario gallego, con población muy dispersa y donde el acceso al médico oficial resultaba imposible, la medicina popular se ha seguido practicando en este siglo, al menos durante sus cuarenta primeros años (6).

La vigencia de la medicina popular manifiesta la pervivencia de la cultura popular. En el s. XVI y primeros años del XVII las élites participan también de la cultura popular, y la misma ciencia y medicina académica no logra distanciarse suficientemente de ella.

En la cultura y medicina popular el diablo constituye uno de los elementos esenciales; hecho que también se da en la medicina morisca. Para los sanadores moriscos el demonio es, por una parte, un doméstico, o «familiar», o criado cuyo control le permite sobrepasar las fuerzas naturales; por otra se le identifica con la enfermedad, por lo que los demonios deben ser expulsados para que el enfermo sane. En ambos casos el médico-sanador está dotado de poderes extranaturales que le permiten obtener unos objetivos más allá de lo posible en el mundo real. Esta superación de lo imposible a través del dominio sobre el «demonio familiar» corresponde a la más genuina cultura popular (7).

Tenemos el caso de Baltasar Capdal, de quien Luis de Sant Felíu, de Morviedro,

(6) Cfr. V. LIS QUIBEN: La medicina popular en Galicia, Pontevedra, 1949; C. LISON COLOSANA: Antropologia cultural de Galicia, Madrid, 1971; J. Comelles: Magia y curandismo en la medicina popular, Barcelona, 1973.

(7) MiKEL DE EPALZA en recensión al trabajo citado de Garcia Ballester -Sharq Al-Andalus, n. ${ }^{\circ} 2$, Alicante, 1985, pp. 271-272- precisa la importancia de vincular la demonología de los médicos moriscos con el Islam. Corresponde a los islamológos subsanar estas carencias y desarrollar la hipótesis que plantea. Pero no hay duda de que la cultura popular conecta en distintos puntos de encuentro con la teología cristiana e islámica, aunque su fondo sea común y anterior a ambas confesiones religiosas. 
cristiano viejo, testifica que aquél le ha confesado «que el tenía un demonio familiar y su amo tenía dos, que es un granadino que está en Buñol (...) y el dicho demonio le traía las yerbas que él quería aunque fuesen de los montes de Armenia». También el morisco Francisco Zafar testimonió ante la Inquisición que «el dicho Capdal cura por arte de demonio, y le vio porque dentro de un aposento de la casa del dicho Valenciano estaba el dicho Capdal con un libro donde traya muchas figuras de demonios, y echo unas ojas de yedra que fueron tres en una caçuela de agua, y alli el demonio señaló que lavasen al dicho Lucas en la fuente del Turis» (8).

Jerónimo Pachet, médico morisco, confiesa la implicación del diablo en sus curaciones; "dixo qué al principio, quando tomó al demonio, curaba muchas con él porque éste dependía, y de catorze o quinze años a esta parte que éste ya tenía experiencia y conocía las propiedades de las yerbas y medicinas, no se a probechado del demonio si no es en algún negocio grabe, que éste no entendía por medios naturales, y los médicos [universitarios] los dexaban por muertos» (9). El morisco parece justificar el recurso al demonio en los casos límite, cuando la medicina académica no podía resolver la enfermedad. No es novedad que en casos desesperados se recurra a la medicina popular y curanderil, con frecuencia ligada a la magia.

El control sobre los demonios se había conseguido mediante conjuros. Así Jerónimo Pachet confesó «que él a tenido ligado en una plancha al demonio para que acudiese quando le llamase, y que el alfaquí de Benimodo le dio dos demonios ligados en dos planchas para éste. Y que la una la dio a los señores Inquisidores la otra bez que estuvo preso, y se quedó con la otra plancha y la tiene en su casa». Los inquisidores le habían interrogado anteriormente sobre sus relaciones con el demonio de la plancha: «preguntado si sin la dicha plancha a llamado al dicho familiar alguna vez, y si le llamase si vendría, dixo que siempre lo a llamado con la plancha y a venido, y que quando no tenía la plancha le a llamado y no a venido.

Preguntado qué señal y muestra dará este confensante de que haya hecho lo que tiene dicho con su familiar, y cómo le mostraría ser así verdad, porque el dicho señor Inquisidor lo quiere ver, dixo que él no es alfaquí, ni saber leer ni screvir, ni conjurar al familiar, ni tampoco tiene poder para ello más que para solamente hazer lo que éste a confesado, que es para lo que a este se lo dieron.

Preguntado la fuerça de tener este familiar y la substancia, si consiste en el consentimiento de llamarle o en la plancha que tenía, dixo que toda la sustancia estava en la plancha en nombre de éste, y aunque todo el mundo tomase la dicha plancha no se aprovecharía della, porque el familiar estava conjurado solo para éste» (10).

Por tanto los poderes supranaturales le han venido a Pachet del conjuro de un alfaquí, mientras los de Román Ramírez procedian de su abuelo, que había sido un famoso médico. Se crió — dice R. Ramírez-con su abuelo Juan de Luna «que era gran médico como tiene dicho, y siendo este confesante de edad de diez a doze años, e estando para morir el dicho su abuelo, le dixo a este confesante que si se

\footnotetext{
(8) AHN. Inquisición, Valencia, legajo 549, núm. 19

(9) AHN. Inquisición, Valencia, legajo 840, núm. 20

(10) Ibídem.
} 
viese en alguna necesidad entre onze y doze de la noche este confesante llamase y dixese "liarde", que se dexaba ordenado y mandado acudiese a socorrer a éste, y que éste entendió que Liarde era un demonio con quien el dicho su abuelo tenía pacto, y le oyó algunas vezes hablar con él de noche estando con su abuelo en la cama...» (11).

Entre los datos que aparecen en la documentación inquisitorial consultada, no se citan casos de moriscos que acudan a médicos cristianos viejos para remediar sus enfermedades. Sin embargo hay constancia reiterada de que los cristianos viejos reclaman la asistencia de los sanadores moriscos, aunque suele tratarse de enfermos desahuciados por la medicina académica.

A veces la enfermedad no era muy convencional. Así D. Antonio Mexía de Tovar, hermano del prior de la Santa Iglesia de Segovia y estudiante de la Universidad de Alcalá, estaba enfermo y algunos dijeron que se encontraba hechizado; por ello acudieron al morisco Francisco de Córdoba, con fama de curar esta enfermedad. Entre los remedios que el médico aplica a D. Francisco se citan echar polvo en la habitación del enfermo y de la mujer de quien se sospechaba, la revisión del vestido del enfermo y la aplicación de un jubón de una cedulilla escrita con la sangre de una golondrina que el mismo morisco mató «porque no le hiciesen más mal las mujeres» (12). Pero los cristianos viejos no sólo recurren a los sanadores moriscos en casos de enfermedad, sino en otras ocasiones en que sus deseos no pueden conseguirse por medios naturales. Un tema frecuente en la medicina popular es la de remediar la impotencia sexual, que jamás se atribuye a causas fisiológicas, sino a diversos procesos mágicos de unos presuntos rivales. Así Jaime Gorri, cristiano nuevo, intentó remediar a Miguel Alegre, cristiano viejo y vecino de Alcira, «para que pudiese tratar con mugeres porque no podía por estar ligado, y que se le avia de dar scriviendole sobre las palmas de las manos ciertas palabras sacadas de un libro scrito en arábigo, de invocaciones de demonios» (13). A través de la impotencia sexual se expresa en la cultura popular la angustia ante la muerte y el ansia de sobrevivir más allá de su deseo personal.

A veces los cristianos viejos, no menos que los moriscos, recurren a los poderes mágicos del sanador morisco para conseguir cosas que nada tienen que ver con la salud, ni con temas fisiológicos; estos poderes pueden no tener relación con los demonios.

A Jerónimo Capdal «acudian algunas personas a consultarle sobre el santo que saldría en las suertes (...) y que allí solía acudir un fraile de S. Agustín, que no sabe cómo se llama, que venía a preguntar por las suertes que saldrían; pero que muchas vezes le oyó dezir que no havía salido el santo que decía Capdal, y que todo lo que Capdal hazía lo tiene por embuste y disparate" (14).

Una situación semejante revela el testimonio de Jerónimo Taña ante la Inquisición, refiriéndose al cristiano nuevo Jaime Gorri de quien dijo «que una doncella que

(11) Archivo Diocesano de Cuenca. Inquisición, legajo 343, n. ${ }^{\circ} 4876$, ff. 224'-227'.

(12) AHN. Inquisición, Toledo, legajo 192, núm. 4.

(13) AHN. Inquisición, Valencia, legajo 352, núm. 35

(14) AHN. Inquisición, Valencia, legajo 349, núm. 19 
se llamaba Sebastiana contó y refirió a este confesante, que el dicho Gorri le habia hecho un hechizo dándole unos papeles scritos para que un carpintero la quisiese bien y se casara con ella, y que no le avían aprovechado» (15).

A veces es el mismo médico morisco quien se ofrece a sus pacientes para solucionarles problemas que nada tienen que ver con la enfermedad. El catalán Juan Salva y de Alberti, tratado de un dolor de los carcañales de los pies por el médico morisco Gaspar Capdal, se encuentra apesadumbrado por un pleito familiar en relación con una herencia; el médico le dice que «conosçia un amigo cristiano nuevo que savía mucho y conosçia la naturaleza y propiedad de todas las plantas, y que entre ellas sabía una que valía para reducir a amigos y quitar todas desgracias y enemistadas (...) y que el dicho morisco su amigo tenía avilidad para hazer que en la casa de su tío de éste, que es en un lugar de Cataluña que se llama Llangostera, oviese ruido y aparesciesen visiones, y que savia él también hazer cosa con que estarían todos los de la dicha casa y el dicho su primo de éste enfermos» (16).

No hay duda de que estos sanadores moriscos son de una parte los epígonos del Islam y de la medicina arábiga, mientras por otra están inmersos en la cultura popular, en la medicina popular.

Sobre su mayor o menor asimilación del Islam no parece haber dudas. El adoctrinamiento y práctica del Islam, en el caso de Román Ramírez, fue tardío; podemos suponer que no sería la excepción, al menos entre los moriscos castellanos. Confiesa Ramírez: «la verdad es que por el año de 53, siendo este confesante mozo de treze u catorze años y estando en casa de los dichos sus padres, tenían un criado que se llamaba Jerónimo de Villaverde, natural de Ferrer en el Reyno de Aragón, el qual fue el primero que enseñó a éste a ser moro, y que el fundamento que tubo fue que el susodicho estando orando por el mes de mayo en una heredad de su padre d'este, fue este confesante a llevarle de comer al mediodía y no quiso comer, diziéndole a este confesante "quita de ay, que eres un perro; ¿yo había de comer ahora?" Hágote saber que es ahora el mes de Ramadán y que el que le ayuna se ba derecho al cielo. No comas como tus padres. Yo te quiero decir cómo salvarás tu alma, y lo que has de hazer para ello. As de ayunar de estrella a estrella, y no as de comer ni bever bocado. $Y$ as de creer en un solo dios verdadero. $Y$ si quieres ir a Terrer por doze o treze dias, quando haya acabado el servicio de tu padre, yo te enseñaría todas las cosas que hazen los moros. Y mira que te amonesto de parte de dios que lo hagas y bayas conmigo para que sirvas a dios y no al diablo como sirven tus padres» (17).

Posteriormente, perdido el contacto con Villaverde y casado con Angela de Miranda, cesó de practicar el ayuno durante once o doce años. Estando en Aragón volvió a ayunar; más tarde tuvo ánimo de convertirse a la fe católica, y estuvo más de veinte años sin hacer ceremonia de moros «aunque siempre se le inclinava el corazón a ser moro, y andava vacilando consigo sobre qual hera mejor ley, la de los

(15) AHN. Inquisición, Valencia, legajo 552, núm. 53.

(16) AHN. Inquisición, Valencia, legajo 549, núm. 19.

(17) Arhivo Diocesano de Cuenca. Inquisición, legajo $343, n .^{\circ} 4876$, ff. 211'-213'. 
moros o de los christianos, y en qual se había de salvar». Un esclavo turco del capitán Cabrera, que vivía en Deza, le convenció de la ley de los moros (18).

Del doctor Jerónimo Jabar se dice que «no comía tozino, aunque bibía vino, diziendo que el tozino le hazía mal en el estómago" (19); Jabar acabará sus años en Argel, vestido de moro, visitando las mezquitas y ejerciendo de boticario y médico allí.

De Francisco de Córdoba, natural de Menizneca, en África, sabemos que cumplía con el Ramadán, el guadoch y la çala. Su creencia religiosa islámica y su inmersión en la cultura popular, le van a enfrentar por partida doble con el clero católico.

La cultura popular trata de explicar el mundo visible a través de un mundo invisible de espíritus - animismo- o de fuerzas diversas - animatismo - que puede ser dominado mediante acciones mágicas. Es conocida la tensión entre magia y religión (20).

El clero, sobre todo el rural, se encuentra inmerso en una sociedad en la que la cultura popular está aún viva; su formación escolástica le proporciona, por otra parte, una comprensión de su fe religiosa desde la razón, heredada de la cultura griega; su creencia racionalizada le llevará a rechazar el animismo y la magia que caracterizan a la cultura popular, pero puede encontrar en el diablo un punto de confluencia de las tres cosmovisiones de las que participa: la cultura popular, la razón y la creencia religiosa. El peso de cada uno de los tres elementos culturales que confluyen en el clero variará según se trate de clérigos vinculados al mundo rural, o -en el otro extremo- los eclesiásticos que integraban el Consejo de la Suprema Inquisición.

Es curioso el caso de Juan de Ortigosa, cura del lugar de Madruédano, del obispado de Osma, y que a la sazón contaba 50 años de edad. Fue a Tajahuerce a conjurar a Bartolomé de Ortega, el mozo, y a su mujer Ana Sanz, pues se decía que estaban endemoniados. Ortigosa se convenció de ello pues durante los exorcismos y oraciones Bartolomé de Ortega le descubrió que estaba poseído por tres demonios, Satanás, Barrabás y Belcebú. Acabada la novena, salieron los tres del cuerpo de Bartolomé de Ortega "dando cada uno su señal, y que las señales que dieron fueron un quartillo de plata de la moneda que corre». Ortega contó cómo le habían poseído los tres demonios: el primero, porque al pedirle a su mujer dinero para jugar, ésta «abía desatado un lienzo con dineros y dádoselo, arrojándolo y diciendo: tomadlo con el diablo»; el segundo y el tercero entraron al recoger media agujeta y un clavo de agujeta que un muchacho y la suegra de Ortega habían tirado al suelo al rompérseles, exclamando «anda con el diablo». Se advierte la virtud mágica de la palabra, algo propio de la cultura popular de la que participan tanto el cura como el «endemoniado».

Añade el clérigo de Madruédano que eran los demonios quienes hablaban por Bartolomé de Ortega, y «aunque sonava su voz se entiende era de los espíritus ma-

\footnotetext{
(18) Ibidern, f. 212.

(19) AHN. Inquisición, Valencia, legajo 552, núm. 9.

(20) WELTER, G.: Les croyances primitives et leurs survivances, Paris, 1960, pp. 13 y 98-99; MAUSS, M.: Sociologie et anthropologie, París, 1966, p. 15.
} 
los que tenía; y que a este testigo le decía muchas injurias y cosas que no las podía saber si no era demonio; y le amenaçaron a este testigo que entre Almaçan y Berlanga abían de hazer una hoguera y abían de quemar a este testigo, y que este testigo les respondió que no eran parte para ello ni la tenían sobre él; y que biniendo por el camino, mas acá de la benta que está entre esta dicha villa de Berlanga y la de Almazán, repentinamente se vino un nublado tan solamente sobre este testigo, de manera que temió que fuese cosa de los dichos espíritus, y este testigo sacó una cruz que traya consigo en el pecho y unas reliquias, y dixo algunas oraciones con que fue Dios servido que el nublado pasase adelante sin ofensa deste testigo". Indudablemente no se había desprendido de la cultura popular.

Con Ana Sanz los conjuros y exorcismos tardaron más en surtir efecto, pues «aunque la susodicha tenía muchas señales de estar endemoniada, nunca este testigo pudo rendir los espíritus que en ella estaban, ni hacerles manifestar quiénes eran».

Más tarde le llaman de nuevo para que continúe los conjuros a Ana y «se manifestó un demonio que no se acuerda determinadamente cómo dixo que se llamaba; y preguntándole este testigo que cuántos eran le respondió que ciento y uno o cientos y tantos, y que preguntándole dónde estaban los demás, respondió que habían ydo a la villa de Deça a ver a Román Ramírez o a ber lo que mandava, unas destas dos cosas, y que no saldrían de alli hasta que él diese licencia para ello, y apretándole este testigo para que saliese se quedó amorteçida la dicha Ana Sanz (...); preguntándole este testigo qué era lo que abía havido y quién la atormentava y haçía aquel mal, respondió que todo aquel día la habían estado abrasando bruxas, sin nombrar a nadie, y que este testigo no se descuidase porque aquella noche le abían de llebar (...). Pasadas algunas oras, aquella noche, este testigo la hiço acostar y le hiço dar unos garrotes en las piernas porque todo el día había estado traspellados los dientes y apretados fuertemente, y con el dolor de los cordeles abrió un poco la boca quexándose, y este testigo le puso una cruz entre los dientes de manera que por alli le pudiesen echar unas cucharadas de substancia» (21).

El sanador morisco Román Ramírez, en su doble condición de hombre de otra creencia y dotado como sanador de poderes extraordinarios y mágicos, aparece en tratos con el demonio y en cierto modo identificado con él, y por tanto en oposición al clérigo Juan de Ortigosa. Sin duda en la fe de éste pesan más las viejas y populares estructuras mentales que la razón.

Para el inquisidor que condena a estos sanadores moriscos la lejanía de la cultura popular es mayor, pero no tanto como para no participar en ella. Las condenas están motivadas por dos razones que frecuentemente aparecen imbricadas. La primera es por herejes, pues bautizados practican la fe de Mahoma; la segunda por sus poderes extraordinarios a causa de pacto o trato con el demonio.

Son condenados por herejes y por brujos, y en definitiva tampoco los inquisidores escapan del todo a la cultura popular, al creer en el poder mágico de los sanadores moriscos. El ataque a la brujería y magia que caracteriza a la cultura popular se hace desde un cierto maniqueísmo - el diablo sería la causa de los males y aberraciones de la mentalidad popular-.

(21) Archivo D. Cuenca, Inquisición, legajo 343, n. ${ }^{\circ} 4876$, ff. 22-25'. 
Pero la Inquisición española fue en general comprensiva con el tema de la brujería; se conocen inquisidores que adoptaron actitudes plenamente racionales, y veían en las brujas y otras personas acusadas de tener poderes extraordinarios por trato con el demonio como simples charlatanes, farsantes, incluso enfermos (22). Parece que en estos casos el distanciamiento de la cultura popular es total, y el atisbo de un precedente de la nueva mentalidad de las élites que emerge en los últimos años del S. XVII, y tiene su mayoría de edad en el pensamiento ilustrado.

Sin embargo hoy estamos de vuelta de esa visión unidimensional del hombre concebido a partir de la llustración como solo razón. La vuelta de una medicina heterodoxa en las sociedades avanzadas se ha producido porque la enfermedad no traduce con frecuencia un conflicto únicamente orgánico, sino que es además psicológico y social, y la medicina académica solo ha respondido al problema orgánico (23). En este sentido la medicina popular, tan pobre en recursos farmacológicos, estaba mejor provista para subsanar las tensiones psicológicas y sociales.

\section{Conclusión}

En esta comunicación se ha aludido a muchos problemas que merecerían un trato individualizado en profundidad.

En primer lugar el rechazo que se da en la sociedad española de los s. XV, XVI y XVII a las lenguas árabe y hebrea, y en general a la cultura árabe, son datos que evidencian la mutilación de una realidad plural. La asunción de la intolerancia europea, que podía ser útil para mantener la homogeneidad de los paises centrales europeos, resultó traumática para un país de tres religiones y dos culturas.

Además en los sanadores moriscos confluyen otros problemas. Uno de ellos es la relación entre la ciencia oficial y cultura popular. Una segunda cuestión importante es la conexión entre cristianismo y magia, entre Islam y magia; finalmente otro gran tema a dilucidar es si el aplastamiento y explotación de un grupo social por otro es más decisivo que la creencia religiosa que los define; dicho de otra manera, qué es más estructural o más superestructural, el enfrentamiento desigual de dos grupos fuertemente cohesionados, o la ideología religiosa que los identifica.

Son temas que quedan abiertos a un debate y a nuevas profundizaciones.

(22) Cfr. HENNINGSEN, G.: El abogado de las brujas. Brujeria vasca e Inquisición española, Madrid, 1983; CA. RO BAROJA, J.: Las formas complejas de la vida religiosa, Madrid, 1985, etc.

(23) Cfr. Los estudios del biólogo francés HENRI LABORIT. 